\title{
Formyl Peptide Receptor 1 and 2 Dual Agonist Inhibits Human Neutrophil Chemotaxis by the Induction of Chemoattractant Receptor Cross-desensitization
}

\author{
Yoshitaka Sogawa $^{1}$, Takao Ohyama ${ }^{2}$, Hiroaki Maeda ${ }^{3}$, and Kazuki Hirahara ${ }^{3, *}$ \\ ${ }^{1}$ Cardiovascular-Metabolics Research Laboratories, Daiichi Sankyo Co., Ltd., \\ 1-2-58 Hiromachi, Shinagawa-ku, Tokyo 140-8710, Japan \\ ${ }^{2}$ Biologics Research Laboratories, ${ }^{3}$ Frontier Research Laboratories, Daiichi Sankyo Co., Ltd., \\ 1-16-13 Kitakasai, Edogawa-ku, Tokyo 134-8630, Japan
}

Received July 22, 2010; Accepted November 17, 2010

\begin{abstract}
Formyl peptide receptor 1 (FPR1) and FPR2/ALX are known to control neutrophil chemotaxis in response to various ligands. In this study, we investigated the inhibitory mechanism of compound 43 (Cpd43), an FPR1 and FPR2/ALX dual agonist, on human neutrophil chemotaxis. Precedent stimulation of human peripheral blood neutrophils with Cpd43 rendered the cells unresponsive in calcium mobilization induced by interleukin-8, C5a, or leukotriene $\mathrm{B}_{4}$. In addition, neutrophils pretreated with $\mathrm{Cpd} 43$ lost their chemotactic responses against these chemoattractants, wherein the expressions of chemoattractant receptors CXCR1, CXCR2, C5a receptor, and leukotriene $\mathrm{B}_{4}$ receptor 1 on the surface of neutrophils were all diminished significantly by treatment with Cpd43. By evaluating its pharmacological effect on 341 molecules, including receptors and enzymes, we also confirmed that Cpd43 has a highly specific affinity to FPR1 and FPR2/ALX and does not show binding affinity to the other chemoattractant receptors. These results indicate a previously unrecognized inhibitory mechanism of $\mathrm{Cpd} 43$ on neutrophil chemotaxis: the induction of cross-desensitization of multiple chemoattractant receptors in human neutrophils through its FPR1 and FPR2/ALX dual agonism.
\end{abstract}

Keywords: formyl peptide receptor, neutrophil, chemotaxis, cross-desensitization

\section{Introduction}

Neutrophils are crucial in the host defense against microorganisms (1), but excessive accumulation of neutrophils could also contribute to the pathogenesis of chronic inflammatory diseases $(2-4)$. Neutrophils migrate into inflamed sites along the gradient of pathogenand/or host-derived neutrophil chemoattractants such as $N$-formyl-Met-Leu-Phe (fMLF), interleukin (IL)-8, complement component $\mathrm{C} 5 \mathrm{a}$, and leukotriene $\mathrm{B}_{4}\left(\mathrm{LTB}_{4}\right)$ (5). These chemoattractants bind to their specific receptors on neutrophils and induce cell activation and chemotaxis. Therefore, pharmacological intervention of neutrophil chemotaxis targeting chemoattractant recep-

*Corresponding author. hirahara.kazuki.s2@daiichisankyo.co.jp Published online in J-STAGE on December 14, 2010 (in advance) doi: 10.1254/jphs.10194FP tors would lead to therapeutic benefit in the treatment of chronic inflammatory diseases.

Human neutrophils express formyl peptide receptor 1 (FPR1) and FPR2/ALX, which are known to be involved in controlling neutrophil chemotaxis in response to various ligands such as FPR1-selective fMLF and FPR2/ ALX-selective lipoxin $\mathrm{A}_{4}$ (reviewed in Ref. 6). Recently, it has been reported that the nonpeptidyl pyrazolone compound 43 (Cpd43), an FPR1 and FPR2/ALX dual agonist (described as Compound A in Ref. 7), inhibited human neutrophil chemotaxis towards IL-8 and fMLF (8), but its mechanism of action on chemoattractant receptors on human neutrophils is largely unknown.

In this study, we investigated the inhibitory mechanism of Cpd43 on the chemotactic responses of human peripheral blood neutrophils towards various chemoattrantants, such as IL-8, C5a, and $\mathrm{LTB}_{4}$, by evaluating calcium flux, chemotaxis, and receptor expression. We also investi- 
gated the pharmacological activity of $\mathrm{Cpd} 43$ in the panel assay by evaluating its effect on 341 molecules, including receptors and enzymes, to confirm the specificity of Cpd43 to FPR1 and FPR2/ALX.

\section{Materials and Methods}

\section{Reagents}

$N$-Formyl peptide fMLF and $\mathrm{LTB}_{4}$ were purchased from Sigma-Aldrich (St. Louis, MO, USA). Recombinant human IL-8 and human C5a were purchased from R\&D Systems (Minneapolis, MN, USA). The peptide WKYMVM (Trp-Lys-Tyr-Met-Val-Met-NH2) was purchased from Tocris (Ellisville, MO, USA). All cell culture media used in this study were purchased from Life Technologies (Carlsbad, CA, USA). Fluo 4-acetoxymethyl ester (AM) and Calcein-AM were purchased from Dojindo Laboratories (Kumamoto). Carboxyfluorescein-conjugated human CXCR1 monoclonal antibody (mAb) (clone 42705), phycoerythrin-conjugated human CXCR2 mAb (clone 48311), and carboxyfluoresceinconjugated human $\mathrm{LTB}_{4}$ receptor 1 (BLT1) mAb (clone 203/14F11) were purchased from R\&D Systems. Phycoerythrin-conjugated human $\mathrm{C} 5 \mathrm{a}$ receptor $(\mathrm{C} 5 \mathrm{aR}) \mathrm{mAb}$ (clone C85-4124) and phycoerythrin-conjugated human $\mathrm{CD} 11 \mathrm{~b}$ mAb (clone ICRF44) were purchased from BD Biosciences (Palo Alto, CA, USA). Cpd43 [N-(4chlorophenyl)- $N^{\prime}$-(5-isopropyl-1-methyl-3-oxo-2phenyl-2,3-dihydro-1H-pyrazol-4-yl)urea] was synthesized in the Medicinal Chemistry Research Laboratories at Daiichi Sankyo.

\section{Isolation of human neutrophils}

All experiments using human materials were reviewed and approved by the Institutional Ethical Committee at Daiichi Sankyo. Venous blood anti-coagulated with sodium heparin was obtained from healthy volunteers. Neutrophils were purified by sequential preparation of sedimentation with dextran sulfate T-500 and density centrifugation with Ficoll-Paque. The erythrocytes were removed by hypotonic shock. The isolated human neutrophils were washed with Hanks' balanced salt solutions supplemented with $20 \mathrm{mM}$ 4-(2-hydroxyethyl)-1-piperazineethanesulfonic acid (HEPES) and $5 \mathrm{mM}$ EDTA and then resuspended in buffer suitable for each assay. The purity of isolated neutrophils was routinely $>95 \%$ as assessed by light microscopic analysis of the cells stained with Diff-Quick (Wako Pure Chemical Industries, Osaka), and the cells were $>98 \%$ viable as assessed by a trypan blue exclusion test.

\section{Measurement of calcium mobilization}

Isolated human neutrophils were suspended in Iscove's modified Dulbecco's medium supplemented with $0.5 \%$ BSA. Cells were incubated with $4 \mu \mathrm{M}$ Fluo4-AM and $0.16 \%$ pluronic acid (Life Technologies) at $37^{\circ} \mathrm{C}$ in $5 \%$ $\mathrm{CO}_{2}$ for $30 \mathrm{~min}$. The cells were washed and resuspended in the medium. The cells were prestimulated with Cpd43 at room temperature for $30 \mathrm{~min}$ and subsequently stimulated with $1 \mathrm{nM} \mathrm{IL-8,} 0.1 \mathrm{nM} \mathrm{C} 5 \mathrm{a}$, or $10 \mathrm{nM} \mathrm{LTB} 4$ without a washout step. Calcium mobilization was detected with a flow cytometer (Cytomics FC500; Beckman Coulter, Fullerton, CA, USA) as a change in the fluorescence intensity in neutrophils. Mean fluorescence intensity (arbitrary units) in the 5-s period immediately before and after stimulation was calculated. Assays were performed in duplicate. Results are expressed as mean fluorescence intensity.

\section{Chemotaxis assays}

Chemotaxis assays were performed using HTS Transwell-96 plates with 3- $\mu$ m pore (Corning, Lowell, MA, USA). Isolated human neutrophils were suspended in RPMI1640 medium supplemented with $20 \mathrm{mM}$ HEPES. The cells were incubated with Calcein-AM at $37^{\circ} \mathrm{C}$ for $30 \mathrm{~min}$ and then washed and resuspended in RPMI1640 medium supplemented with 20 mM HEPES and $0.1 \%$ BSA. The cells were incubated with various concentrations of $\mathrm{Cpd} 43$ at $37^{\circ} \mathrm{C}$ for $30 \mathrm{~min}$ and then washed twice to remove the compound. The cells were added into the upper wells $\left(2 \times 10^{5}\right.$ cells/well $)$; and $1 \mathrm{nM}$ IL-8, $0.1 \mathrm{nM} \mathrm{C5a}$, or $1 \mathrm{nM} \mathrm{LTB} 4$ was added into the lower wells. The plates were incubated at $37^{\circ} \mathrm{C}$ for $1 \mathrm{~h}$. After removing the upper wells, the migrated cells were lysed with sodium dodecyl sulfate, and the resultant fluorescence intensity was measured with a plate reader (ARVO SX1420; PerkinElmer, Waltham, MA, USA). Assays were performed in duplicate. Results are expressed as the percentage of net migration cells.

\section{Flow cytometric analysis on cell surface receptors}

Human whole blood was incubated with or without various concentrations of $\mathrm{Cpd} 43$ at room temperature for $30 \mathrm{~min}$ and subsequently stained with labeled antiCXCR1, CXCR2, C5aR, or BLT1 mAbs at room temperature for another $30 \mathrm{~min}$ in the presence of $\mathrm{Cpd} 43$. After the erythrocytes were lysed using a human erythrocyte lysing kit (R\&D Systems), the stained cells were washed with wash buffer that was included in the erythrocyte lysing kit and fixed with $2 \%$ paraformaldehyde. The expression of receptors on the neutrophils was analyzed with FACSCanto (BD Biosciences). The data were analyzed using FlowJo software (Tree Star, Ashland, OR, USA). 


\section{Investigation of Cpd43 specificity}

The specificity of Cpd43 was investigated using Spectrum Screen ${ }^{\circledR}$ and Enzyme Spectrum Screen ${ }^{\circledR}$ provided by Ricerca Biosciences (formerly MDS Pharma Services, Taipei, Taiwan). All assays were performed in duplicate using Cpd43 at a final concentration of $10 \mu \mathrm{M}$. Results for selected molecules are expressed as mean \% inhibition.

\section{Results}

Cpd43 desensitizes chemoattractant-induced intracellular calcium mobilization in neutrophils

We previously reported that $\mathrm{Cpd} 43$ has agonistic activities for human FPR1 and FPR2/ALX (7). The $\mathrm{EC}_{50}$ values of Cpd43 for FPR1 and FPR2/ALX were $65 \mathrm{nM}$ and $22 \mathrm{nM}$, respectively, in the aequorin assay that measured calcium mobilization (Table 1). No agonistic activity to FPR3 was observed up to $10 \mu \mathrm{M}$ in the aequorin assay, in which humanin, an FPR3 agonist peptide (9), showed significant agonistic activity (data not shown). In this study, we first investigated the effect of $\mathrm{Cpd} 43$ on intracellular calcium mobilization in human neutrophils. Neutrophils were pretreated with $\mathrm{Cpd} 43$ and subsequently stimulated with IL-8, C5a, or LTB 4 . Pretreatment with Cpd43 dose-dependently inhibited calcium mobilization in human neutrophils stimulated with IL-8, C5a, or $\mathrm{LTB}_{4}$ (Fig. 1). The cells showed calcium mobilization to $100 \mu \mathrm{M}$ ATP stimulation even after pretreatment with $10 \mu \mathrm{M} \mathrm{Cpd43} \mathrm{(data} \mathrm{not} \mathrm{shown),} \mathrm{indicating} \mathrm{that} \mathrm{the} \mathrm{de-}$ creased calcium mobilization observed in the chemoattractant-stimulated cells was not due to cell dysfunction. We also confirmed that Cpd43 had no effects on cell viability up to $10 \mu \mathrm{M}$ (data not shown). These results suggest that pretreatment with Cpd43 heterologously desensitized chemoattractant-stimulated calcium mobilization in human neutrophils.

Table 1. Pharmacological parameters for human FPR1 and FPR2/ ALX

\begin{tabular}{lcc}
\hline \multirow{2}{*}{ Compounds } & \multicolumn{2}{c}{$\mathrm{Ca}^{2+}$ Mobilization $\mathrm{EC}_{50}(\mathrm{nM})^{\mathrm{a}}$} \\
\cline { 2 - 3 } Cpd43 & $\mathrm{FPR} 1$ & $\mathrm{FPR} 2 / \mathrm{ALX}$ \\
fMLF & 65 & 22 \\
WKYMVM & 0.50 & 1100 \\
\hline
\end{tabular}

${ }^{\mathrm{a}} \mathrm{EC}_{50}$ values were calculated from our previously reported results (7) in which calcium mobilization in Chinese hamster ovary cells expressing either human FPR1 or FPR2/ALX was measured. Two peptides were used as control agonists.
Cpd43 attenuates the chemotactic activity of neutrophils

We next investigated the effect of Cpd43 on human neutrophil chemotaxis induced by neutrophil chemoattractants. As Cpd43 itself induces neutrophil chemotaxis (7), we pretreated neutrophils with various concentrations of $\mathrm{Cpd} 43$ and washed it out before using the cells in chemotaxis assays in order to circumvent the effect of its chemotactic activity. Pretreatment with Cpd43 attenu-
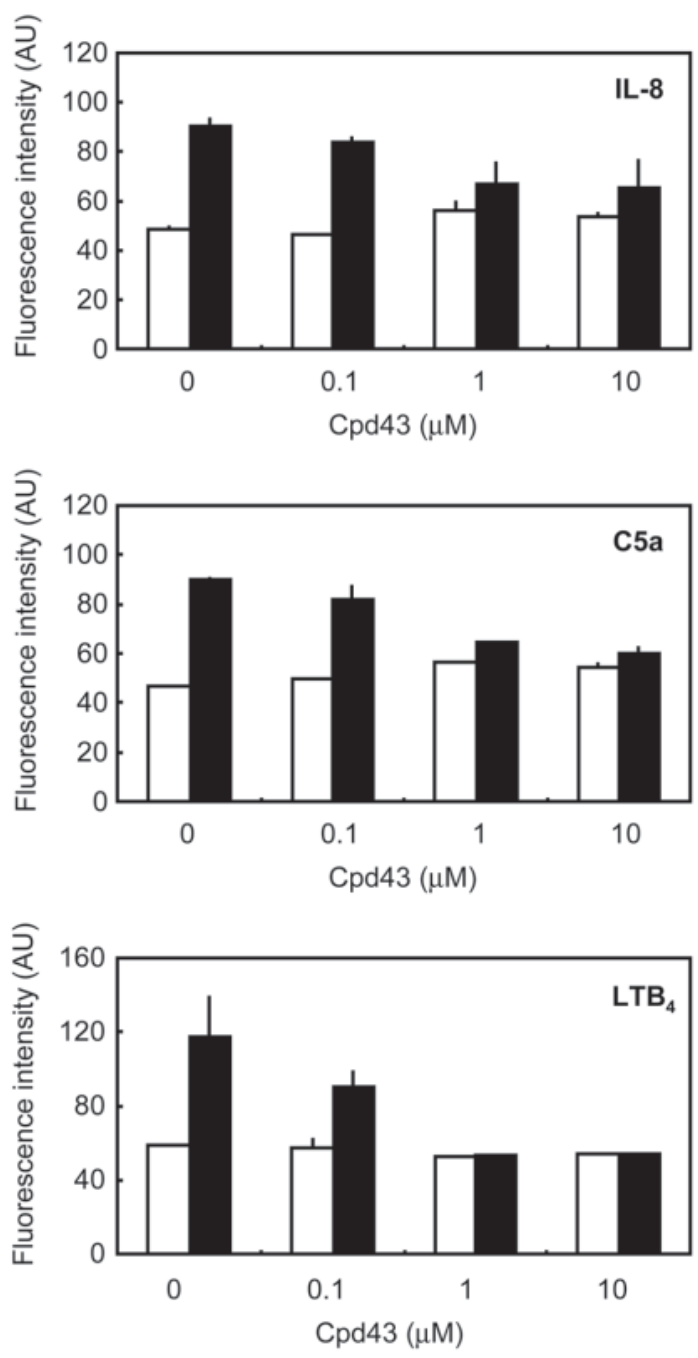

$\square$ Before $\mathbf{A}$ After chemoattractant stimulation

Fig. 1. Cpd43 induces cross-desensitization of the $\mathrm{Ca}^{2+}$ response in neutrophils. Human neutrophils were loaded with Fluo4-AM. The cells were prestimulated with various concentrations of $\mathrm{Cpd} 43$ for 30

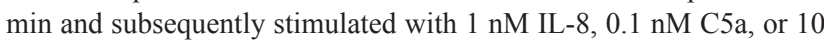
$\mathrm{nM} \mathrm{LTB}_{4}$. Calcium flux at the second stimulation in the cells was analyzed using a flow cytometer. Data (mean \pm S.E.M.) are expressed as the mean fluorescence intensity in the 5-s duration immediately before (white bar) and after (black bar) stimulation. The experiment was performed in duplicate and the representative data of four independent experiments with similar results are shown. AU, arbitrary units. 
ated the chemotactic responses of human neutrophils against IL-8, C5a, or $\mathrm{LTB}_{4}$ in a concentration-dependent manner (Fig. 2).

\section{Cpd43 diminishes the expressions of chemoattractant} receptors on neutrophils

We conducted a flow cytometric analysis to determine whether Cpd43 affected the expressions of chemoattractant receptors on human neutrophils. Human neutrophils were incubated with various concentrations of Cpd43 for $30 \mathrm{~min}$, and the expressions of CXCR1, CXCR2, C5aR, and BLT1 on the surface of the cells were measured. Incubation with $\mathrm{Cpd} 43$ diminished the expressions of these receptors (Fig. 3A). The expression of $\mathrm{CD} 11 \mathrm{~b}$, one of the surface activation markers on neutrophils, was increased by Cpd43 incubation (Fig. 3B). Therefore, stimulation of neutrophils with Cpd43 specifically altered the expressions of the chemoattractant receptors. Our findings so far strongly suggest that Cpd43 induced hetero-desensitization (cross-desensitiza-

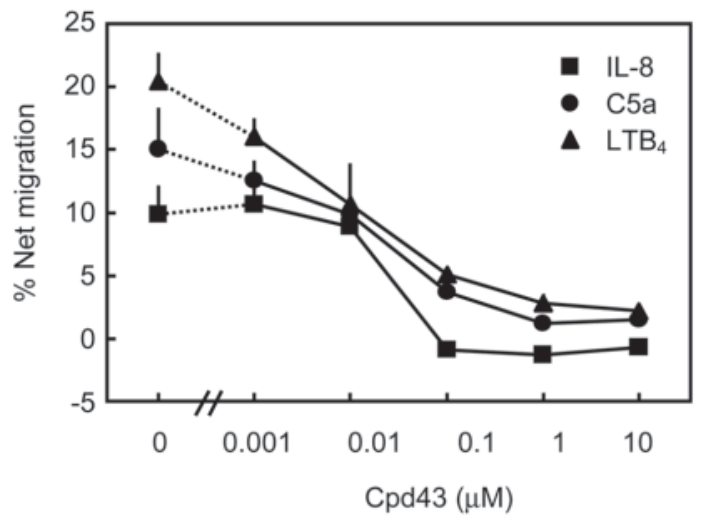

Fig. 2. Pretreatment of $\mathrm{Cpd} 43$ inhibits neutrophil chemotaxis induced by several chemoattractants. Human neutrophils were preincubated with various concentrations of $\mathrm{Cpd} 43$ at $37^{\circ} \mathrm{C}$ for $30 \mathrm{~min}$ and washed twice to remove the compound. Chemotaxis of these cells was induced by $1 \mathrm{nM}$ IL-8, $0.1 \mathrm{nM} \mathrm{C5a}$, or $1 \mathrm{nM} \mathrm{LTB}$. Data (mean \pm S.E.M.) are expressed as the percentage of net migrated cells. The experiment was performed in duplicate and the representative data of four independent experiments with similar results are shown.
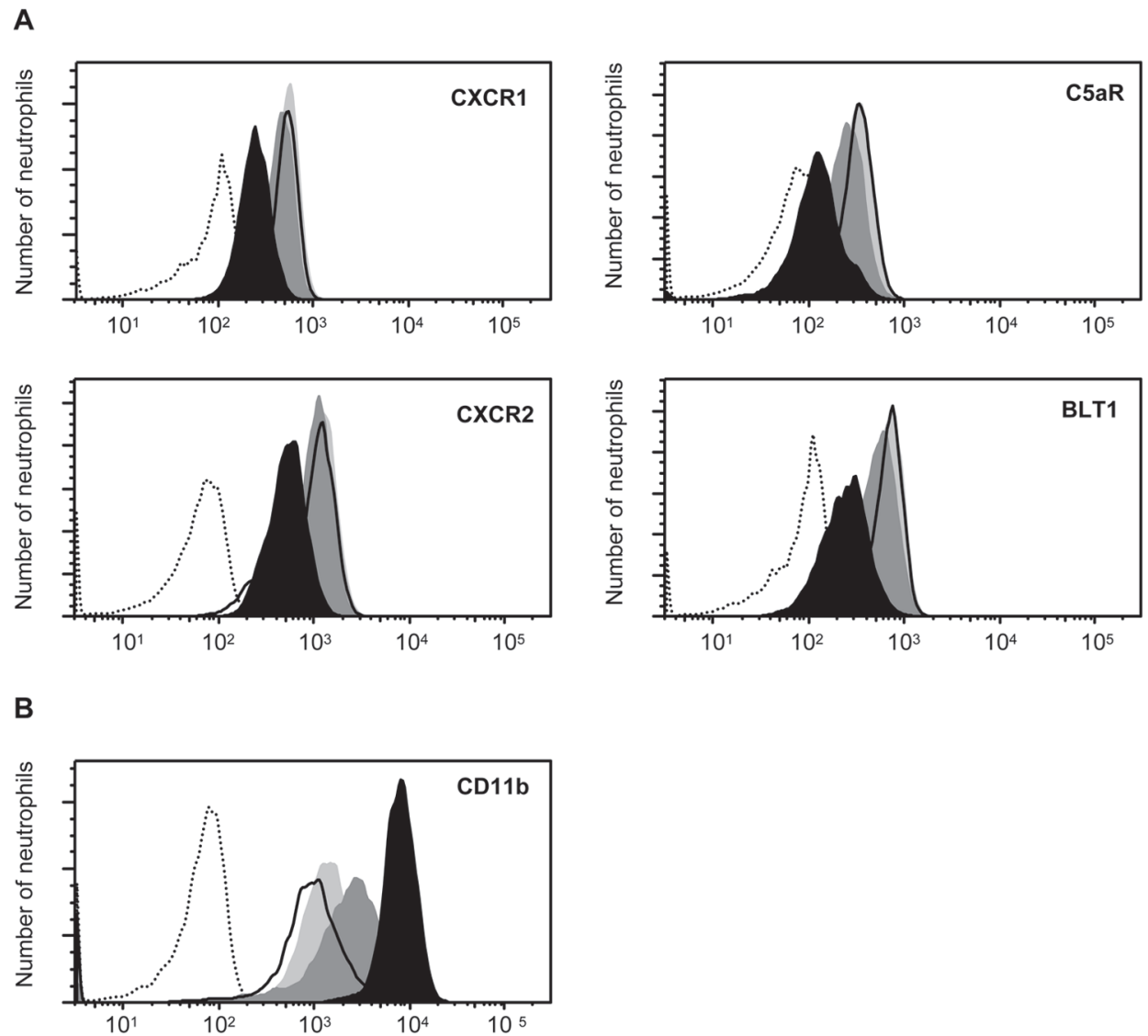

Fig. 3. Cpd43 diminishes the expression of chemoattractant receptors on neutrophils. Human whole blood was incubated with or without various concentrations of $\mathrm{Cpd} 43$ at room temperature for $30 \mathrm{~min}$ and subsequently stained with antibodies. After the erythrocytes were lysed, the expression of chemoattractant receptors (A) and CD11b (B) on neutrophils was analyzed with a flow cytometer. Representative data of four different experiments with similar results are shown. Each histogram represents cells that were treated with $\mathrm{Cpd} 43$ at $0 \mu \mathrm{M}$ (solid line), $0.1 \mu \mathrm{M}$ (light gray), $1 \mu \mathrm{M}$ (gray), or $10 \mu \mathrm{M}$ (black). The dotted line represents the unstained control. 
tion) of the chemoattractant receptors in human neutrophils through its FPR1 and FPR2 agonism and rendered the cells unresponsive to stimulation with several chemoattractants.

\section{Cpd43 shows high specificity to FPRs}

To rule out the possibility that Cpd43 inhibited human neutrophil chemotaxis by mechanisms other than the induction of cross-desensitization, we next investigated the inhibitory effects of Cpd43 on 341 molecules (168 receptors, channels, and transporters in radioligandbinding assays and 173 enzymes in enzymatic assays) at a concentration of $10 \mu \mathrm{M}$. Cpd43 significantly inhibited the binding between FPR1 and $\left[{ }^{3} \mathrm{H}\right] \mathrm{fMLF}$ and also between FPR2/ALX and $\left[{ }^{125}\right.$ I]WKYMVM peptide with $104 \%$ and $89 \%$ inhibition, respectively. For molecules other than FPRs, Cpd43 showed modest inhibitory effects only on a dopamine transporter and cytochrome P450 2D6 (63\% and 66\% inhibition, respectively). No significant inhibitions were observed for other targets, including neutrophil chemotaxis-related molecules such as CXCR2, C5aR, BLT1 (Table 2), and p38 mitogenactivated protein kinase (data not shown). These results demonstrated that Cpd43 was highly specific for FPR1 and FPR2/ALX and thus we concluded that Cpd43 inhibited human neutrophil chemotaxis by the induction of cross-desensitization through the stimulation of FPRs.

\section{Discussion}

In this study, we have demonstrated a previously unrecognized inhibitory mechanism of $\mathrm{Cpd} 43$ on human neutrophil chemotaxis: the cross-desensitization of multiple chemoattractant receptors in human neutrophils.

We showed that treatment with Cpd43 inhibited neu-

Table 2. Inhibitory effect of $\mathrm{Cpd} 43$ on various molecules

\begin{tabular}{lc}
\hline Target molecule $^{\mathrm{a}}$ & \% Inhibition $^{\mathrm{b}}$ \\
\hline FPR1 & 104 \\
FPR2/ALX & 89 \\
Cytochrome P450 2D6 & 66 \\
Dopamine transporter & 63 \\
CXCR2 & 7 \\
C5aR & 7 \\
BLT1 & 4 \\
\hline
\end{tabular}

${ }^{\mathrm{a} A}$ total of 341 molecules including receptors, channels, transporters, and enzymes were tested. The molecules for which Cpd43 showed significant inhibition and chemoattractant receptors for IL-8, C5a, and $\mathrm{LTB}_{4}$ used in this study are selected. ${ }^{\mathrm{b}} \%$ Inhibition at a concentration of $10 \mu \mathrm{M} \mathrm{Cpd} 43$ in the ligand binding assay and enzymatic assay. trophil responses to IL-8, $\mathrm{C} 5 \mathrm{a}$, or $\mathrm{LTB}_{4}$ in the calcium mobilization and chemotaxis assays. The results suggest that Cpd43 widely inhibits human neutrophil response to multiple chemoattractants. It is known that some chemoattractants, such as fMLF and C5a, activate neutrophils and desensitize not only their specific receptors (homologous desensitizaiton) but also other chemoattractant receptors (cross-desensitization) in the cells $(10-13)$. Homologous desensitization occurs in the agonist-stimulated receptor itself in the agonist-occupied state. On the other hand, cross-desensitization occurs in receptors that are unrelated to the agonist-stimulated receptor. The mechanism of cross-desensitization is not clearly understood, but it has been theorized that co-activation of adjacent receptors, which could be enabled by a shared signaling process, should be taking place between the ligand-specific and unrelated chemoattractant receptors (14).

Moreover, we showed that $\mathrm{Cpd} 43$ attenuated the expressions of multiple chemoattractant receptors. The mechanism of diminished receptor expression on neutrophils is considered to be the receptor internalization associated with cross-desensitization which is induced after the transient cell activation $(14,15)$. It has been reported that $\mathrm{PMLF}$ attenuated the CXCR2 expression, but not CXCR1, following the induction of cross-desensitization (15). The significant effect of Cpd43 on the expression of receptors, including CXCR1, might be attributed to its FPR1 and FPR2/ALX dual agonistic activity because both FPR1 $(10-13)$ and FPR2/ALX $(16-18)$ are known to induce cross-desensitization. The detailed molecular mechanism of Cpd43-induced internalization of the receptors has not yet been elucidated.

We conducted the panel assay to clarify the pharmacological acitvity of Cpd43 and showed the high specificity of Cpd43 to FPR1 and FPR2/ALX. Cpd43 also showed a modest effect on the dopamine transporter and cytochrome P450 2D6, except for FPRs. The dopamine transporter regulates the transport of monoamine neurotransmitter dopamine in the neurons (19), and cytochrome P450 2D6 is one of the important enzymes involved in the metabolism of xenobiotics in the liver (20). Currently, there are no reports demonstrating that these molecules are expressed in neutrophils or are related to neutrophil chemotaxis. Since Cpd43 did not show any significant inhibition of CXCR2, C5aR, or BLT1 in the ligand binding assays, our results indicate that $\mathrm{Cpd} 43$ induced the cross-desensitization of the chemoattractant receptors in human neutrophils through its FPR1 and FPR2/ALX dual agonism and inhibited cellular responses to the chemoattractants.

The induction of chemoattractant receptor crossdesensitization in neutrophils might become a novel ap- 
proach for the treatment of neutrophil-related inflammation. Some chemoattractant receptor antagonists are currently being developed for the treatment of neutrophilrelated inflammations such as chronic obstructive pulmonary disease (21). However, their efficacy might not be sufficient because a number of chemoattractants are produced at the site of inflammation. A cross-desensitization inducer should be an effective drug because it can inhibit responses to multiple chemoattractants simultaneously. Indeed, we found that oral administration of $\mathrm{Cpd} 43$ inhibited neutrophil migration into airways in LPS-exposed mice, possibly by the induction of cross-desensitization in vivo (22). These results suggest that agonist compounds for FPRs, like Cpd43, may work as functional antagonists for multiple chemoattractant receptors and may have therapeutic benefit on neutrophil-related inflammation in humans. In the future, it is necessary to evaluate the potential side effects of the compounds because neutrophils are involved in host defense, and thus, excess reduction of neutrophil numbers and function might result in increased susceptibility to infection.

In conclusion, we have found that $\mathrm{Cpd} 43$, a highly specific agonist for FPR1 and FPR2/ALX, induced cross-desensitization of multiple chemoattractant receptors in human neutrophils and inhibited cell chemotaxis toward multiple chemoattractants.

\section{Acknowledgments}

The authors would like to thank Dr. Hitoshi Kurata for providing Cpd43 and Dr. Akiko Shimizugawa for her assistance in performing the aequorin assays and providing helpful advice. We also gratefully thank Dr. Shinichi Kurakata for his critical review of the manuscript and for his insightful comments.

\section{References}

1 Kobayashi SD, Voyich JM, Burlak C, DeLeo FR. Neutrophils in the innate immune response. Arch Immunol Ther Exp (Warsz). 2005;53:505-517.

2 Abraham E. Neutrophils and acute lung injury. Crit Care Med. 2003;31:S195-S199.

3 Jatakanon A, Uasuf C, Maziak W, Lim S, Chung KF, Barnes PJ. Neutrophilic inflammation in severe persistent asthma. Am J Respir Crit Care Med. 1999;160:1532-1539.

4 Stockley RA. Neutrophils and the pathogenesis of COPD. Chest. 2002;121:151S-155S.

5 Springer TA. Traffic signals for lymphocyte recirculation and leukocyte emigration: the multistep paradigm. Cell. 1994;76: 301-314.

6 Ye RD, Boulay F, Wang JM, Dahlgren C, Gerard C, Parmentier $\mathrm{M}$, et al. International Union of Basic and Clinical Pharmacology. LXXIII. Nomenclature for the formyl peptide receptor (FPR) family. Pharmacol Rev. 2009;61:119-161.

7 Sogawa Y, Shimizugawa A, Ohyama T, Maeda H, Hirahara K. The pyrazolone originally reported to be a formyl peptide recep- tor (FPR) 2/ALX-selective agonist is instead an FPR1 and FPR2/ ALX dual agonist. J Pharmacol Sci. 2009;111:317-321.

8 Burli RW, Xu H, Zou X, Muller K, Golden J, Frohn M, et al. Potent hFPRL1 (ALXR) agonists as potential anti-inflammatory agents. Bioorg Med Chem Lett. 2006;16:3713-3718.

9 Harada M, Habata Y, Hosoya M, Nishi K, Fujii R, Kobayashi M, et al. N-Formylated humanin activates both formyl peptide receptor-like 1 and 2. Biochem Biophys Res Commun. 2004;324: 255-261.

10 Didsbury JR, Uhing RJ, Tomhave E, Gerard C, Gerard N, Snyderman R. Receptor class desensitization of leukocyte chemoattractant receptors. Proc Natl Acad Sci U S A. 1991;88: 11564-11568.

11 Kitayama J, Carr MW, Roth SJ, Buccola J, Springer TA. Contrasting responses to multiple chemotactic stimuli in transendothelial migration: heterologous desensitization in neutrophils and augmentation of migration in eosinophils. J Immunol. 1997; 158:2340-2349.

12 Richardson RM, Ali H, Tomhave ED, Haribabu B, Snyderman R. Cross-desensitization of chemoattractant receptors occurs at multiple levels. Evidence for a role for inhibition of phospholipase C activity. J Biol Chem. 1995;270:27829-27833.

13 Tomhave ED, Richardson RM, Didsbury JR, Menard L, Snyderman R, Ali H. Cross-desensitization of receptors for peptide chemoattractants. Characterization of a new form of leukocyte regulation. J Immunol. 1994;153:3267-3275.

14 Ali H, Richardson RM, Haribabu B, Snyderman R. Chemoattractant receptor cross-desensitization. J Biol Chem. 1999;274: 6027-6030.

15 Sabroe I, Williams TJ, Hebert CA, Collins PD. Chemoattractant cross-desensitization of the human neutrophil IL-8 receptor involves receptor internalization and differential receptor subtype regulation. J Immunol. 1997;158:1361-1369.

16 Deng X, Ueda H, Su SB, Gong W, Dunlop NM, Gao JL, et al. A synthetic peptide derived from human immunodeficiency virus type 1 gp120 downregulates the expression and function of chemokine receptors CCR5 and CXCR4 in monocytes by activating the 7-transmembrane G-protein-coupled receptor FPRL1/ LXA4R. Blood. 1999;94:1165-1173.

17 Li BQ, Wetzel MA, Mikovits JA, Henderson EE, Rogers TJ, Gong W, et al. The synthetic peptide WKYMVm attenuates the function of the chemokine receptors CCR5 and CXCR4 through activation of formyl peptide receptor-like 1. Blood. 2001;97: 2941-2947.

18 Shen W, Proost P, Li B, Gong W, Le Y, Sargeant R, et al. Activation of the chemotactic peptide receptor FPRL1 in monocytes phosphorylates the chemokine receptor CCR5 and attenuates cell responses to selected chemokines. Biochem Biophys Res Commun. 2000;272:276-283.

19 Howell LL, Kimmel HL. Monoamine transporters and psychostimulant addiction. Biochem Pharmacol. 2008;75:196-217.

20 Zanger UM, Raimundo S, Eichelbaum M. Cytochrome P450 2D6: overview and update on pharmacology, genetics, biochemistry. Naunyn Schmiedebergs Arch Pharmacol. 2004;369:23-37.

21 Barnes PJ. New molecular targets for the treatment of neutrophilic diseases. J Allergy Clin Immunol. 2007;119:1055-1062.

22 Sogawa Y, Ohyama T, Maeda H, Hirahara K. Inhibition of neutrophil migration in mice by mouse formyl peptide receptors 1 and 2 dual agonist: Indication of cross-desensitization in vivo. Immunology. In press. doi: 10.1111/j.1365-2567.2010.03367.x. 